\title{
Lung transplantation during the outbreak of Coronavirus Disease 2019 in China
}

Bo Wu, MD, ${ }^{\text {a }}$ Man Huang, MD, ${ }^{\mathrm{b}}$ Guohui Jiao, MD, ${ }^{\mathrm{a}}$ Chunxiao Hu, MD, ${ }^{\mathrm{a}}$ Yi Yang, MD, ${ }^{\mathrm{c}}$ and Chen Jingyu, MD, ${ }^{a, d}$ China Lung Transplantation Alliance, National Lung Transplantation Expert Group for COVID-19*

\section{ABSTRACT}

Objectives: The study objectives were to illustrate our workflow for lung donation and transplantation during the Coronavirus Disease 2019 crisis and to report our preliminary experience with perioperative care.

Methods: We retrospectively analyzed data in the China Lung Transplantation Registration from January 23, 2020, to March 23, 2020 (2020 cohort), compared with the same period in 2019 (2019 cohort). Pre- and post-lung transplantation management strategies, including measures aiming to prevent severe acute respiratory syndrome coronavirus 2 infection, were applied to all recipients, including 5 post-Coronavirus Disease 2019 transplants during the Coronavirus Disease 2019 pandemic period in China.

Results: Twenty-eight lung transplant procedures were performed, including lung transplant for 5 patients with acute respiratory distress syndrome due to Coronavirus Disease 2019-related pulmonary fibrosis. Compared with the 2019 cohort, more patients with urgent conditions received transplantation in 2020 , with a shorter prelung transplant admission time and early mobilization post-lung transplant. A large proportion (60\%) of lung donations were transported on high-speed trains and commercial flights or highways and commercial flights. Grafts in the preservation containers were handed over to the receiving staff at the airport for $40 \%(10 / 25)$ of donations, which reduced the unnecessary quarantine of transporting staff entering the city. Listed candidates were urgently transferred to other qualified centers in $17.9 \%$ of cases (5/28), which reduced the risk of severe acute respiratory syndrome coronavirus 2 exposure in Coronavirus Disease 2019-designated hospitals. The 90-day survival of the transplant recipients in 2020 was $85.7 \%$, including 3 of 5 recipients $(60 \%)$ who had critically severe Coronavirus Disease 2019.

Conclusions: Lung transplant and donation amid Coronavirus Disease 2019 can be performed safely with coordinated efforts on medical resource sharing and medical staff protection based on stratification of the infection risk. Outcomes were not compromised during the Coronavirus Disease 2019 outbreak. Lung transplantion can be regarded as salvage therapy for critical patients with Coronavirus Disease 2019 with a confirmed positive turned negative virology status. (J Thorac Cardiovasc Surg 2022;163:326-35)

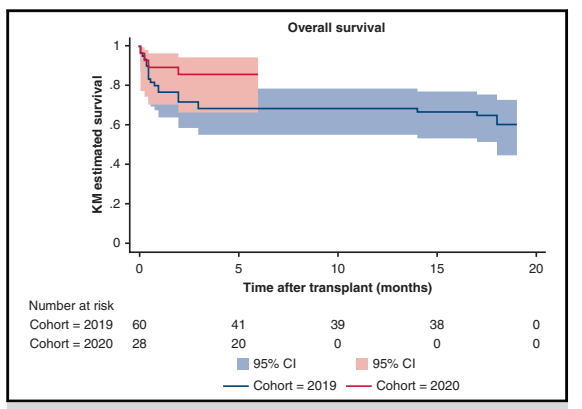

Overall survival of LTx recipients by Kaplan-Meier plots comparing the outcome of patients who received a transplant during January 23 to March 23, 2019 (cohort 2019) and 2020 (cohort 2020).

\section{CENTRAL MESSAGE}

Lung donation and transplantation amid COVID-19 were performed safely and could be the salvaging therapy for critical patients post-COVID-19.

\section{PERSPECTIVE}

Candidates' referral and transplantation can be adopted with coordinated effort on medical resource sharing and medical staff protected according to the stratification of infection risk. Short-term follow-up of transplant recipients with critically severe COVID-19 with confirmed positive turned negative virology status demonstrated a promising result.

See Commentaries on pages 336 and 337.
From the ${ }^{\text {a} W u x i ~ L u n g ~ T r a n s p l a n t ~ C e n t e r, ~ W u x i ~ P e o p l e ' s ~ H o s p i t a l ~ a f f i l i a t e d ~ t o ~ N a n j-~}$ ing Medical University, Wuxi, China; ${ }^{\mathrm{b}}$ General ICU, Second Affiliated Hospital, Zhejiang University School of Medicine, Hangzhou, China; ${ }^{\mathrm{C}}$ Department of Critical Care Medicine, Zhongda Hospital, School of Medicine, Southeast University, Nanjing, China; and ${ }^{\mathrm{d}}$ Center for Lung Transplantation, China-Japan Friendship Hospital, Beijing, China.

Research funding from Science and Technology Office of Wuxi City for "lung transplantation as therapeutic option for COVID-19-related critical patients" (N2020X002).

B.W. and M.H. contributed equally to the work.

* Members of the China Lung Transplantation Alliance and National Lung Transplantation Expert Group for COVID-19 are listed in the Acknowledgments.
Received for publication June 17, 2020; revisions received Oct 30, 2020; accepted for publication Oct 30, 2020; available ahead of print Dec 1, 2020.

Address for reprints: Yi Yang, MD, Department of Critical Care Medicine, Zhongda Hospital, School of Medicine, Southeast University, Nanjing, China (E-mail: yiyiyang2004@163.com); and Jingyu Chen, MD, Wuxi Lung Transplant Center, Wuxi People's Hospital affiliated to Nanjing Medical University, Qing Yang Rd, No 299\#, Wuxi, China 214023 (E-mail: chenjy@ wuxiph.com). $0022-5223 / \$ 36.00$

Copyright (C) 2020 by The American Association for Thoracic Surgery https://doi.org/10.1016/j.jtcvs.2020.10.154 


\section{Abbreviations and Acronyms \\ BMI = body mass index \\ CLTA = China Lung Transplantation Alliance \\ COVID-19= Coronavirus Disease 2019 \\ ECMO $=$ extracorporeal membrane oxygenation \\ ICU = intensive care unit \\ Ig = immunoglobulin \\ LTx $\quad=$ lung transplantation \\ MV $\quad=$ mechanical ventilation \\ NAT $\quad=$ nucleic acid test \\ SARS-COV-2 $=$ severe acute respiratory syndrome coronavirus 2}

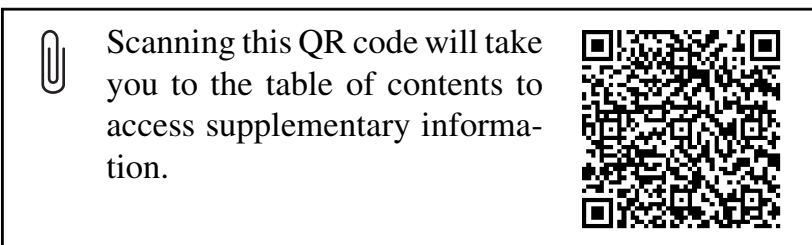

Severe acute respiratory syndrome coronavirus 2 (SARSCoV-2)-induced Coronavirus Disease 2019 (COVID-19) is a global pandemic that is wreaking havoc worldwide. ${ }^{1}$ Sustained community transmission of the virus continues despite the adoption of precautionary measures, such as quarantine and temporary city lockdowns. The "new normal" post-COVID-19 pandemic era may permanently change our previous model of medical care. The COVID-19 outbreak in cities saturated the healthcare system and decreased organ donation and transplantation activity because of the risk of cross-infection with unrecognized viral shedding by potential donors and recipients. ${ }^{2}$ For transplantation centers, the balancing of resources to ensure the safety of recipients, listing candidates, and professionals while carrying out elective and urgent lung transplantation (LTx) surgeries remains a considerable challenge. Publications and guidelines on screening donors, assessing recipients, and preventing the risk of SARS-CoV-2 infection emerged. ${ }^{3,4}$ However, evaluations of the LTx performed during the COVID-19 outbreak remain scarce.

We collected LTx data from the time when the city of Wuhan declared a state of emergency and imposed a lockdown with containment measures on January 23, 2020, to provide our experience in the management and prompt resumption of LTx activity during the unprecedented outbreak of COVID-19. The number of existing confirmed COVID-19 cases decreased in China after February 15, and candidates listed for LTx were gradually admitted to LTx centers. Donated grafts were transported as a result of a collaborative effort by the China Lung Transplantation Alliance (CLTA) $)^{5}$ (detailed information is provided in Appendix E1). We further documented post-LTx outcomes, including data from 5 recipients who had critical COVID19 with confirmed positive turned negative virology status (hereafter referred to as patients post-COVID-19) to confirm the feasibility and safety of performing lung donation and transplantation in the midst of the COVID-19 pandemic.

\section{MATERIALS AND METHODS \\ Study Population}

We retrospectively analyzed nationwide data in the Chinese LTx registry from January 23, 2020, to March 23, 2020 (2020 cohort). Data collected from January 23, 2019, to March 23, 2019 (2019 cohort), were used as a benchmark for outcomes in 2020. Because the study used a retrospective design and data were analyzed anonymously, this study was exempt from ethical approval and the requirement of obtained informed consents from patients. This study was conducted in compliance with the provisions of the Declaration of Helsinki.

\section{Ethics}

The Institutional Ethics Committees of all the qualified centers approved the procedures, including verbal consent procedures and data collection. Written informed consent was obtained from the patients and next of kin. The transplanted organs were obtained from volunteer donations, and the next of kin voluntarily provided written informed consent. No lungs were obtained from executed prisoners. ${ }^{5}$ The Institutional Ethics Committees of the Organ Procurement Organization approved the donation procedures. Donor lungs were allocated through the China Organ Transplant Response System (https://www.cot.org.cn/) with comprehensive consideration of factors, such as the recipient's body size, blood type, and urgency status; the locations of the donors and recipients; and the time spent on the waiting list. The National Transplant Medical Review Board (Chinese Lung Transplantation Society and Transplantation Data Management \& Quality Control Center) approved and registered the donors' and recipients' data (Figure E1).

\section{Organ Donation, Allocation, and Logistics}

The routine protocol for donated lung transportation and transplantation in China was based on the CLTA-coordinated workflow after September 2018 (Appendix E1). ${ }^{5}$ Special measures were applied during the COVID-19 pandemic to protect medical staff and recipients from the risk of infection. Collaboration was implemented among the members of the CLTA. Lung recovery teams and transplantation teams participated in the online discussion and shared the donor's medical information with continuous updates. Inter-city quarantine policies were considered before scheduling procured lung transportation. If long-distance transportation was anticipated, staff from the procurement team transported the organ preservation containers to the airport in the receiving city. The donated grafts were handed over to receiving staff at the airport, and the transporting staff returned directly to their resident city on the next outbound flight.

During the COVID-19 pandemic, some of the transplant team members, who were also proficient with critical care or extracorporeal membrane oxygenation (ECMO) maintenance, were called to support designated hospitals in Wuhan and served as auxiliary medical teams in Wuhan. Centers in other cities were designated as COVID-19 hospitals, and medical resources were reallocated per local government policies. Therefore, key personnel and medical resources from various transplant centers were diverted to 
Wuhan and patients with COVID-19, which imposed a strain on the staff of individual centers in the capacity to offer LTx services. At the onset of the expected surge of COVID-19 cases, all elective lung surgeries were temporarily canceled in Wuxi People's Hospital, which hosts the largest LTx program in China ${ }^{6}$ but was designated for the care of patients with COVID-19. Candidates waiting in Wuxi center were transferred to Hangzhou center (located $\sim 200 \mathrm{~km}$ away) if their conditions allowed them to tolerate transportation in an effort to protect immunosuppressed and vulnerable patients from the risk of developing COVID-19. Transplant physicians and surgeons jointly cared for patients with experienced transplant critical care staff.

In addition, the Wuxi team prepared another transplant center called "Wuxi Communicable Diseases Hospital" with full transplant equipment and isolation facilities to receive patients post-COVID-19 for LTx (Table E1). The transfer plans were prepared according to the transplant center's capacity, candidates' locations, regional risk of infection, and medical insurance policies.

\section{Variables}

In general, the registry collected pretransplant baseline data, posttransplant data at hospital discharge, and annual follow-up data. Baseline data included the date of transplantation, age at transplantation, gender, body mass index (BMI), blood type, and the primary diagnostic indication for LTx. Donor characteristics, including age, BMI, blood type, donation type, size match, the fraction of inspired oxygen, and ventilation time, were collected.

Perioperative and postoperative factors, such as mechanical ventilator (MV) or ECMO use before and after transplantation, intensive care unit (ICU) duration, and hospitalization duration, were analyzed. The registry received survival data from participating sites and collectives. Patient status (including living, dead, and lost to follow-up) was recorded. Follow-up data were collected through July 31, 2020, with censoring at the last known follow-up before this date. As we intended to determine the feasibility of LTx during the COVID-19 pandemic, we collected data pertaining to confirmed cases in cities where donation occurred and key events that might affect the national organ donation and transplantation workflow.

\section{Statistics}

Demographic data related to donors, recipients, and transplants were presented as numbers and percentages for categorical variables. Continuous variables were expressed as the mean \pm standard deviation if they exhibited a normal distribution or the median (interquartile range) if they displayed a skewed distribution. Continuous and categorical variables were compared using the Student $t$ test or the Mann-Whitney $U$ test, chisquare, or Fisher exact test as appropriate. Data calculations and comparisons were performed using SPSS version 25 (SPSS Inc, Chicago, Ill) and GraphPad Prism 7 software (GraphPad Software Inc, La Jolla, Calif). Kaplan-Meier plots with calculations were used to assess survival. STATA version 16.0 (StataCorp LP, College Station, Tex) was used to generate Kaplan-Meier plots. A $P$ value less than .05 was considered significant.

\section{RESULTS}

\section{Lung Donation and Transportation}

Twenty-five donated lungs were obtained after brain death of the donors in 2020 cohort. No history of epidemiologic exposure to SARS-Cov-2 was identified in any of the donors. All donors had normal body temperatures over the previous 30 days and normal chest imaging results. Before a donation was accepted, the donor was required to have had at least 2 consecutive negative nasopharyngeal swab nucleic acid test (NAT) results (at least 1 day apart) for SARSCoV-2.

The donor/recipient screening and triage workflow are illustrated in Figure 1. The deceased donor program was

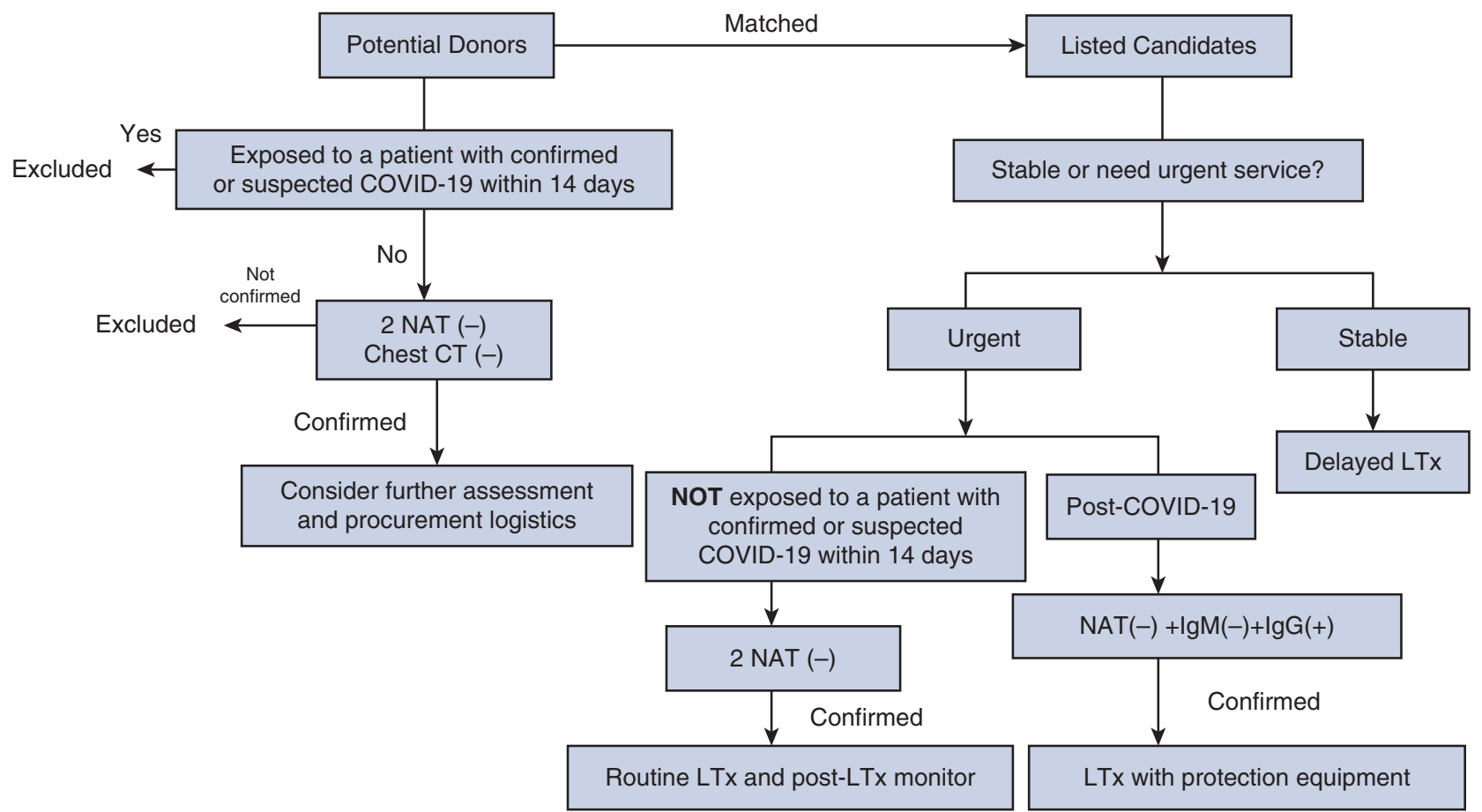

FIGURE 1. LTx donor and recipient screening and triage workflow. COVID-19, Coronavirus Disease 2019; NAT, nucleic acid test; CT, computed tomography; $L T x$, lung transplantation; $I g$, immunoglobulin. 
TABLE 1. Donor characteristics and donated lung transportation

\begin{tabular}{lccc}
\hline & January 23 to March 23, 2019 & January 23 to March 23, 2020 & $P$ value \\
\hline Transportation via GCHOT* $(\%)$ & $19(33.9)$ & $15(60)$ & $725[\mathrm{IQR}, 20-1200]$ \\
Median transportation distance $(\mathrm{km})$ & $300[\mathrm{IQR}, 30-1350]$ & $3.3 \pm 1.7$ & .827 \\
Donated graft transportation time $(\mathrm{h})$ & $3.2 \pm 1.8$ & $39.1 \pm 13.7$ & $7.4 \pm 9.6$ \\
Donor age (y) & $35.6 \pm 13.6$ & .772 \\
Donor on ventilator $(\mathrm{d})$ & $7.5 \pm 9.1$ & $25(100)$ \\
Donor type (\%) & & & .984 \\
DBD & $54(96.4)$ & $2(3.6)$ & \\
DBCD & & \\
\hline
\end{tabular}

GCHOT, Green Channel of Human Organ Transportation; $D B D$, donation after brain death; $D B C D$, donation after brain and cardiac death. *GCHOT was activated when long distance organ transportation was needed, including connection of high-speed train and commercial flight or commercial flight and highway.

suspended in Wuhan, and no donations were accepted from Wuhan in this period. Fifteen $(15 / 25,60 \%)$ donated organs were transported on high-speed trains and commercial flights or highways and commercial flights (Table 1) compared with $33.9 \%(19 / 56)$ in the 2019 cohort. Donations were handed over at the airport in $40 \%$ of cases $(10 / 25)$ in the 2020 cohort. No donations were handed over at the airport in the 2019 cohort. Transferred LTx cases were recorded for $17.9 \%$ of patients ( 5 cases, from Wuxi to Hangzhou). No transferred cases were recorded in the same period of 2019. Transfers occurred between neighboring qualified LTx centers that were also CLTA members, facilitating team collaborations and reducing candidates' waiting time. All patients were transferred without complications or illness exacerbation. The principle of allocating organs to the nearest recipient was still followed. To date, SARS-CoV-2 infection has not been reported in any medical staff involved in the organ donation and transportation process. No significant differences in other donor characteristics were observed between the 2 groups.

\section{Recipients}

In the 2020 cohort, 28 LTx operations were performed, including LTx for 5 patients with acute respiratory distress syndrome due to COVID-19-related pulmonary fibrosis. Twenty-one men $(75 \%)$ and 7 women $(25 \%)$ received transplants, and the average age was $56.6 \pm 15.4$ years (Table 2). The recipients were admitted to 8 centers distributed in 7 cities. In the 2019 cohort, 60 LTx surgeries were performed in 11 centers.

Three high-volume (>30 transplants per year) centers performed 11 LTx operations (39.3\%) in 2020, reflecting a change from the $75 \%$ of LTx cases performed by those centers during the same period in 2019 (Figure E2). However, no significant differences in gender, age, or BMI distributions were identified between the 2 years. Patients with idiopathic pulmonary fibrosis accounted for the highest percentage of patients on the waiting list for LTx $33.3 \%$ in 2019 vs $35.7 \%$ in 2020 ).
Compared with the 2019 cohort, the 2020 cohort had a significantly shortened median time from admission to LTx ( 5 days in 2020 vs 10 days in $2019, P=.012$ ), and these patients had a higher pulmonary artery pressure $(P=.014)$ and a lower partial pressure of oxygen/fraction of inspired oxygen $(P=.025)$ before LTx. Seven LTx recipients $(25 \%)$ in the 2020 cohort received ECMO and mechanical ventilation (MV) support before LTx, including 5 patients post-COVID19. No differences in the number of infection events, the lymphocyte counts, and the levels of inflammatory markers were observed between the 2 groups. Short-term survivals were comparable (Figure 2).

In addition to the 5 transplant recipients post-COVID19, another 9 patients with critical end-stage COVID-19 were also referred to the CLTA committee and National Lung Transplantation Expert Group for COVID-19 for urgent LTx evaluations. Details of the patients' clinical characteristics and preoperative computed tomography images (if available) are shown in Table E2 and Figure E3. Three of the 9 patients $(33.3 \%)$ survived after weaning from ECMO and MV support without transplantation. The other patients who did not receive a transplant (66.7\%) had uncontrollable sepsis, and death could not be avoided. During the COVID-19 pandemic, we performed transplantation in patients post-COVID-19 supported by ECMO within a shorter time (no LTx vs LTx, median time from ECMO to LTx assessment, 57.5 vs 10 days, $P=.00$ ), approximately 1 month after a confirmed diagnosis of COVID-19.

\section{Post-Lung Transplant Surveillance}

Excluding the aforementioned post-COVID-19 LTx recipients, none of the other recipients had epidemiologic exposure to COVID-19. All of these recipients had 2 consecutive negative nasopharyngeal swab results (at least 1 day apart) before they were added to the recipient list. The 5 patients post-COVID-19 were consecutively tested for SARS-CoV-2 using multiple types of specimens, including nasopharyngeal swab, anal swabs, and bronchoalveolar lavage fluid. 
TABLE 2. Characteristics of lung transplant recipients in the same period of 2019 and 2020

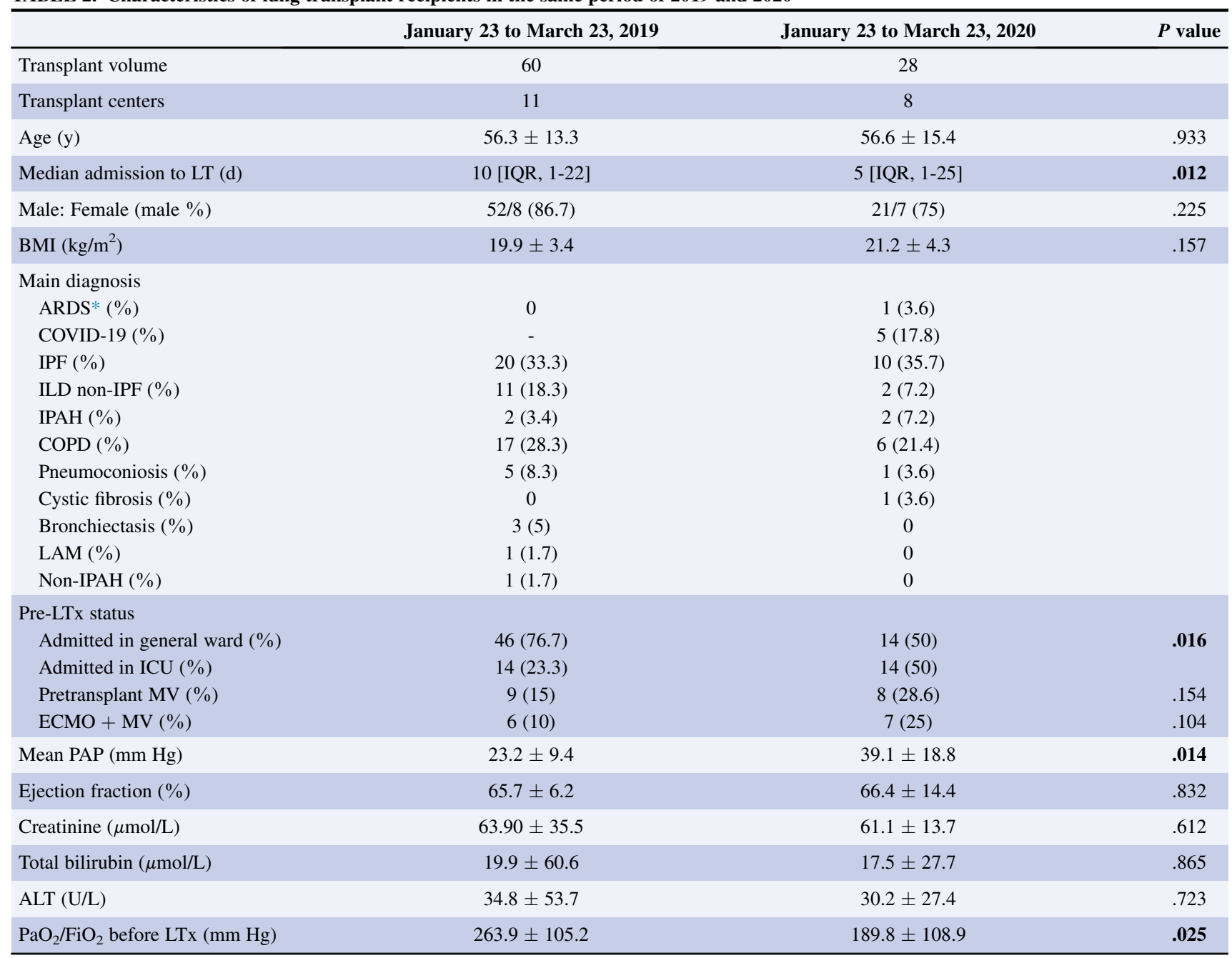

Bold indicates statistical significance $(P<.05)$. $L T$, Lung transplantation; $I Q R$, interquartile range; $B M I$, body mass index; $A R D S$, acute respiratory distress syndrome; COVID- 19 , Coronavirus Disease 2019; IPF, idiopathic pulmonary fibrosis; ILD, interstitial lung diseases; $I P A H$, idiopathic pulmonary artery hypertension; $C O P D$, chronic obstructive pulmonary disease; $L A M$, lymphangioleiomyomatosis; $L T x$, lung transplantation; $I C U$, intensive care unit; $M V$, mechanical ventilation; $E C M O$, extracorporeal membrane oxygenation; $\mathrm{PAP}$, pulmonary artery pressure; $\mathrm{ALT}$, alanine aminotransferase; $\mathrm{PaO}_{2}$, partial pressure of oxygen; $\mathrm{FiO}_{2}$, fraction of inspired oxygen. *Acute respiratory distress syndrome due to non-COVID-19 viral pneumonia.

Among the recipients who received transplantation in the 2020 cohort, 27 patients survived after LTx, and the 30-day survival was $89.3 \%$ (Table 3). Patient 1 , who was the first LTx recipient post-COVID-19, died of uncontrolled bleeding during the procedure. The cause of death for the other patient (patient 5) was severe sepsis. The characteristics of the other patients post-COVID-19 are shown in Table 4. The patients were supported by MV and ECMO (at a median time of 13 days). ECMO was weaned shortly after LTx in the 4 surviving recipients.

Considering the severely impaired immune function of these recipients before LTx, 2 immunosuppressant treatment strategies were considered at the Wuxi Center and Hangzhou Center. Prescriptions were initiated with a lower dose than routinely required, and drug doses were adjusted according to lymphocyte counts and drug plasma concentrations. One recipient treated at the Hangzhou Center presented with acute rejection, and a higher dose of steroid was included as part of the treatment strategy. ${ }^{7}$ Maintenance therapy, including tacrolimus-based and cyclosporine A-based regimens, was initiated at a lower dose and adjusted gradually. During the first month post-LTx, the plasma concentration of tacrolimus was maintained within 6 to $7 \mu \mathrm{g} / \mathrm{L}$ (mean lymphocyte count $0.55 \times 10^{9} / \mathrm{L}$ ). In the cyclosporine A-based regimen, trough levels $(\mathrm{C} 0)$ of cyclosporine A were maintained at an average of $30 \mu \mathrm{g} / \mathrm{L}$, and levels at 2 hours postdose (C2) fluctuated within $100 \mu \mathrm{g} / \mathrm{L}$ (mean lymphocyte count $0.30 \times 10^{9} / \mathrm{L}$ ).

The post-LTx courses and events of the patients postCOVID-19 did not deviate from the general cohort. 


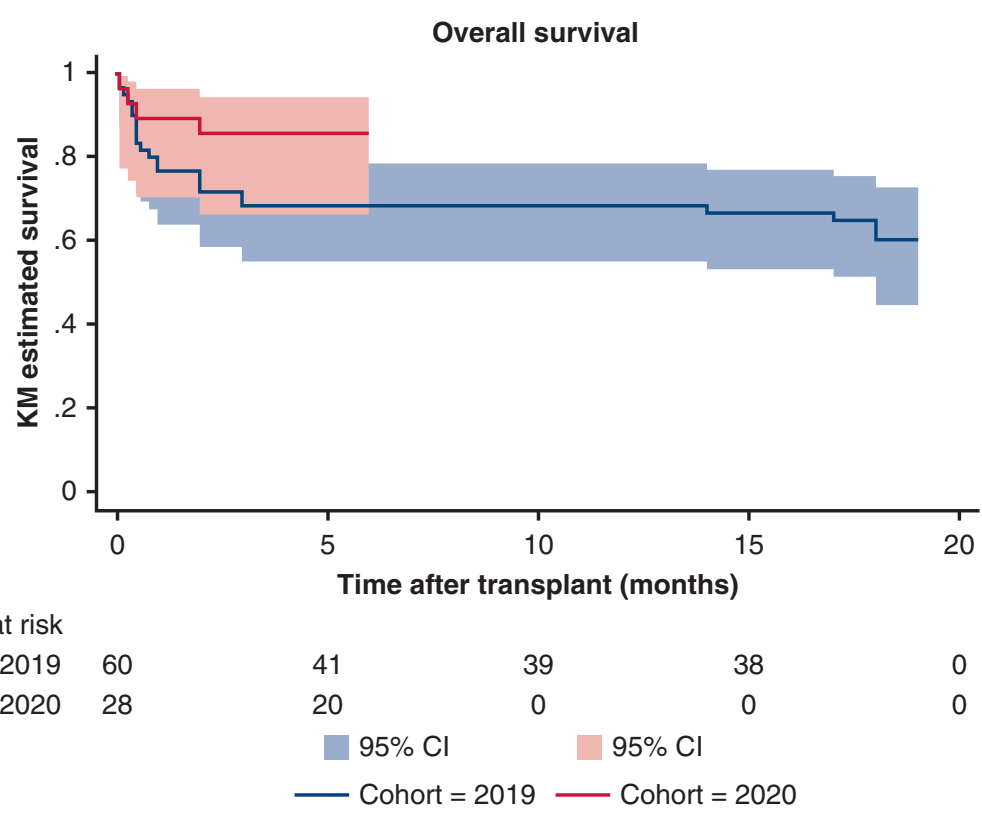

FIGURE 2. Kaplan-Meier plots of the overall survival among recipients who were transplanted during January 23 to March 23 in 2019 (2019 cohort) and 2020 ( 2020 cohort); $\log$-rank $P=.083$. The overall survival of recipients in the 2020 cohort was not inferior to that of the 2019 cohort during the follow-up period. $K M$, Kaplan-Meier; $C I$, confidence interval.

However, all of these patients had extremely low muscle strength due to prolonged intubation with sedation. Therefore, progressive rehabilitation training was warranted, including active mobilization (eg, a bed bicycle), swallowing, breathing exercises, secretion clearance, and posture improvement. Balancing activities, building upper- and lower-extremity range of motion, and active coughing were encouraged. Upon this writing, all the other post-COVID-19 recipients have survived postLTx for 3 months with a lymphocyte count level of approximately $0.8 \sim 1.0 \times 10^{9} / \mathrm{L}$. The 1 -year survival conditional upon discharge for the 2019 cohort was $90.7 \%$, and the 3-month survival post-LTx for the 2020 cohort was $85.7 \%$.

\section{DISCUSSION}

During the COVID-19 pandemic, global recommendations regarding organ donation and transplantation have been released. ${ }^{8-10}$ NATs for SARS-CoV-2 in bronchoalveolar lavage fluid were mandated for screening tissues from deceased donors to ensure the absence of SARS-CoV-2 infection. ${ }^{11}$ Interim precautions, including the screening of care providers and family members who accompanied recipients, were also warranted (Table E3). Personnel involved in donor maintenance, transplant coordinators, personnel certified to make brain death determinations, and Red Cross staff were screened in accordance with national guidelines. ${ }^{12}$ As shown in Figure 3, 80\% of donation procedures were performed after February 15, when most cities in China had a continuously decreasing trend of existing confirmed COVID-19 cases, and LTx activities resumed. With prevention measures, the organ recovery teams and patients transferred to qualified centers were separated from patients with confirmed or suspected COVID-19 to guarantee that LTx proceeded smoothly.

Especially for patients with critical end-stage COVID19, additional screening considerations and principles were applied when they were referred for assessment, were listed, and received LTx. Upon the decision for LTx referral, the patients had refractory respiratory failure dependent on MV/circulation support for at least 1 month without severe hepatorenal or heart failure, and multiple samples negative for SARS-CoV-2 on at least 2 consecutive occasions, with immunoglobulin $(\mathrm{Ig}) \mathrm{M}(-), \mathrm{IgG}(+)$, or $\mathrm{IgG}(-)$. In the 5 transplant recipients post-COVID-19, LTx was considered within 3 weeks of ECMO initiation because guidelines recommended that 21-day ECMO support without lung recovery might be futile. ${ }^{13}$ However, as we learned more about COVID-19 and observed more patients weaning off of ECMO support after more than 3 weeks, the best time for consideration of LTx should be further explored while following up all these recipients. Continuous renal replacement therapy was used more frequently in LTx recipients for nonrenal indications during LTx to remove inflammatory mediators. ${ }^{14}$ All of the referred patients had extremely high lung allocation scores, revealing a "ceiling" effect of lung allocation scores in capturing high-risk features to stratify urgent listed patients with a high mortality rate related to COVID-19. ${ }^{15,16}$ Higher Sequential Organ Failure Assessment scores were also observed in transplant recipients (Table E2). Sequential Organ Failure Assessment scores changed substantially 1 week post-LTx, which indicates a 

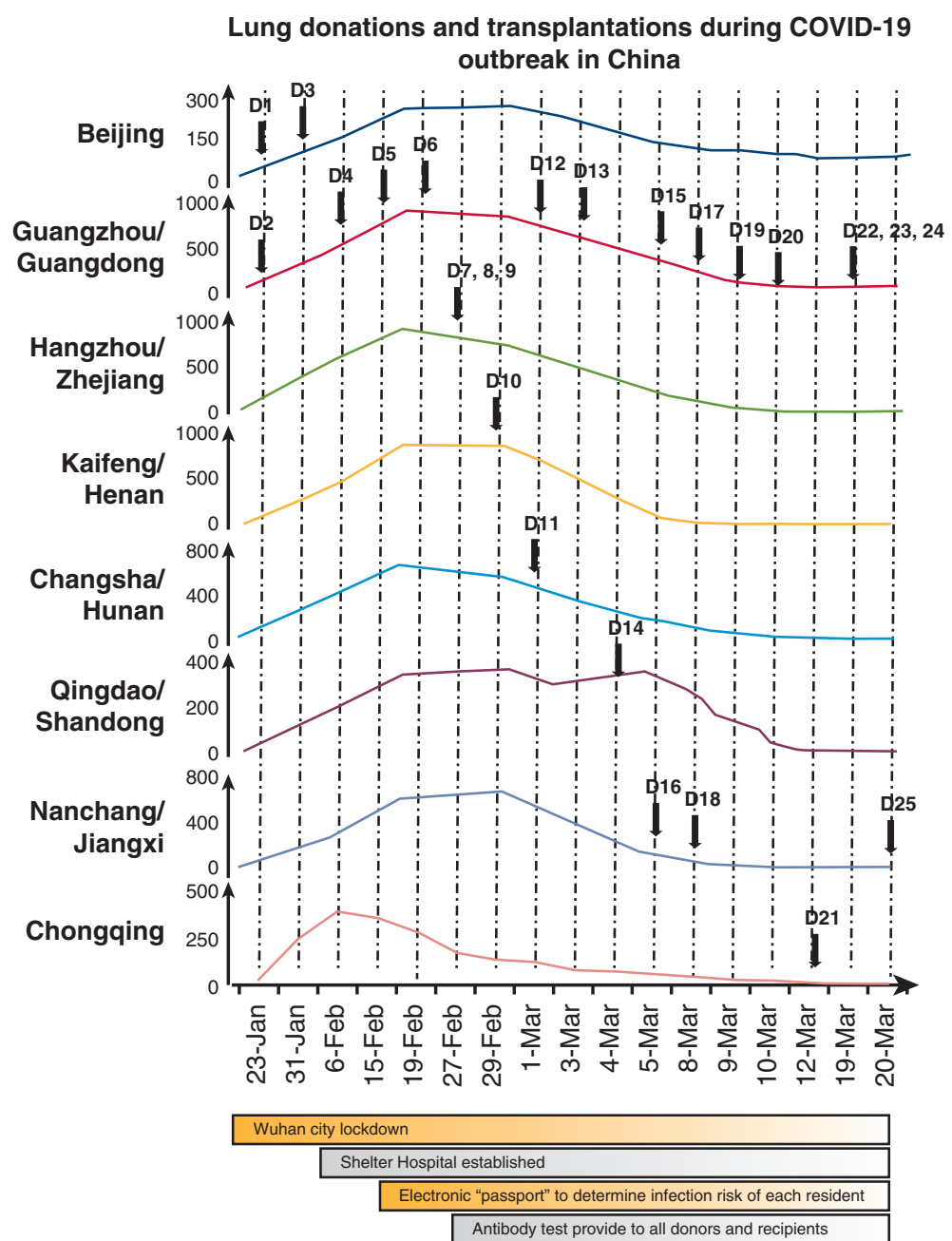

From January $23^{\text {rd }}$ to March $23^{\text {rd }}, 2020,25$ donated lungs were procured and recovered from 8 cities in China, while $80 \%$ performed after February $15^{\text {th }}$ in cities with decreasing trend of confirmed COVID-19 cases. The efforts serve as a basis for management practices of transplant teams to safeguard vulnerable donors, recipients and medical staff during the health crises, such as COVID-19.

FIGURE 3. Time points for lung donation during the COVID-19 epidemic and mitigation measures. Diagram of the COVID-19 epidemic trend in cities and the donors' locations are shown separately. Donation dates and order numbers are also indicated. Bottom: Policies that affected the epidemic trend are shown. The data were referenced from National Health Commission (http://www.nhc.gov.cn/xcs/yqtb/list_gzbd_3.shtml) and visualized from https:// ncov.dxy.cn/ncovh5/view/en_pneumonia. Existing confirmed case statistics are shown at the provincial level. Trends for existing COVID-19 case volumes are depicted by colored lines. COVID-19, Coronavirus Disease 2019.

reduced risk of mortality. ${ }^{17}$ We would recommend LTx be considered for these patients on the basis of organ function, disease course, immune status, and experience of the medical team.

For post-LTx management, we recommended the use of conventional immunosuppressant drugs based on institutional protocols for patients without COVID-19. Earlier initiation of post-LTx rehabilitation and a reduced ICU stay with additional psychological support considerably improved patients' confidence in their survival. We ascribed the relatively shorter ICU stay of the urgent transplant recipients to the reduced case load in the ICU, where only patients without COVID19 were admitted. After weaning from ECMO and intubation, these patients were transferred to single rooms for further treatment.

Because we had taken measures to prevent SARS-CoV-2 infections in non-COVID-19 post-LTx recipients, procedures, such as bronchoscopies, were performed under routine protective conditions. Close cooperation with other departments (eg, radiology) enabled us to prepare single examination units for the recipients. More important, psychologic support and consultations for all medical staff and 
TABLE 3. Characteristics of grafts and recipients' outcomes

\begin{tabular}{|c|c|c|c|}
\hline & January 23 to March 23, 2019 & January 23 to March 23, 2020 & $P$ value \\
\hline Cold ischemic time (h) & $7.6 \pm 2.1$ & $7.1 \pm 1.5$ & .480 \\
\hline Duration of surgery (h) & $5.4 \pm 2.9$ & $5.4 \pm 2.1$ & .905 \\
\hline \multicolumn{4}{|l|}{ Transplantation type } \\
\hline Bilateral $(\%)$ & $28(46.7)$ & $17(60.7)$ & .257 \\
\hline Single* $(\%)$ & $32(53.3)$ & $11(39.3)$ & \\
\hline ICU stay (d) & $11.9 \pm 14.8$ & $\begin{array}{c}7.8 \pm 2.3 \\
\text { (Excluded post-COVID-19) }\end{array}$ & .043 \\
\hline PGD T72h (grade $\geq 2$ ) & $19(31.7)$ & $8(28.6)$ & .810 \\
\hline In-hospital infection episodes $(\%)$ & $45(75)$ & $12(42.8)$ & .004 \\
\hline 30-d survival $(\%)$ & $48(80)$ & $25(89.3)$ & \\
\hline 90-d survival (\%) & $43(71.7)$ & $24(85.7)$ & \\
\hline
\end{tabular}

recipients were provided during the COVID-19 crisis. Most centers imposed a no-visitor policy during the COVID-19 pandemic, but video communication and interactions with families were encouraged for patients admitted to isolation wards. Because of citywide containment measures during the COVID-19 pandemic, recipients were admitted to single rooms for prolonged periods after discharge from the ICU. Evidence from our transplant recipients did not reveal a higher risk of SARS-CoV-2 infection at 5 months after transplantation. Post-LTx infection control was always a big challenge in the 30-day survival of Chinese recipients, and a lower nosocomial infection rate was achieved in the 2020 cohort, which was a significant decrease $(P=.004)$ compared with 2019. Considering the dynamic status of SARS-CoV-2 transmission in the long term, we suggest the adoption of 2 strategies in advance to facilitate scheduled LTx procedures: The inter-center transfer of candidates with a collaborative effort is necessary to avoid COVID-19 exposure in the designated center, and donated lungs transported over long distances are handed over at airports without staff entering cities to avoid requiring quarantine. Strategies based on multi-team collaboration are recommended to guarantee the safety of recipients and post-LTx outcomes.

Reports from heart transplant recipients showed that COVID-19 infections in these patients had a milder

TABLE 4. Post-lung transplant outcomes of patients with acute respiratory distress syndrome due to Coronavirus Disease 2019-related pulmonary fibrosis

\begin{tabular}{|c|c|c|c|c|c|}
\hline & Patient 1 & Patient 2 & Patient 3 & Patient 4 & Patient 5 \\
\hline Transplantation center & Shenzhen* & Wuxi & Hangzhou & Hangzhou & Wuxi \\
\hline From diagnosis to LTx (d) & 35 & 33 & 29 & 35 & 37 \\
\hline From virus clear to LTx (d) & 12 & 9 & 8 & 20 & 16 \\
\hline From ECMO $†$ to LTx (d) & 15 & 7 & 13 & 11 & 19 \\
\hline ECMO weaning post-LTx & - & $37 \mathrm{~h}$ & $5 \mathrm{~d}$ & $2 \mathrm{~d}$ & $40 \mathrm{~h}$ \\
\hline Induction drugs & - & $500 \mathrm{mg} \mathrm{MP}$ & $500 \mathrm{mg} \mathrm{MP} \times 3 \mathrm{~d}$ & $500 \mathrm{mg} \mathrm{MP} \times 3 \mathrm{~d}$ & $500 \mathrm{mg}$ MP \\
\hline Maintenance drugs & - & $\begin{array}{l}\text { Cyclosporine } \\
\mathrm{A} \ddagger+\text { steroids }\end{array}$ & $\begin{array}{c}\text { Tacrolimus } 1 \\
\text { mg every } 12 \mathrm{~h}\end{array}$ & $\begin{array}{c}\text { Tacrolimus } 1 \\
\text { mg every } 12 \mathrm{~h}\end{array}$ & $\begin{array}{l}\text { Cyclosporine } \\
\mathrm{A} \S+\text { steroids }\end{array}$ \\
\hline WBC $\left(\times 10^{9} / \mathrm{L}\right)$ POD 30 & & 4.13 & 2.6 & 3.8 & 5.14 \\
\hline $\mathrm{L}\left(\times 10^{9} / \mathrm{L}\right)$ POD 30 & - & 0.23 & 0.65 & 0.38 & 0.19 \\
\hline CD4/CD8 POD 30 & - & 3.33 & 2.25 & 0.69 & 1.24 \\
\hline Rejection episode & - & No & AR post-LTx $40 \mathrm{~h}$ & No & No \\
\hline Survival status & Death POD 0 & Survived & Survived & Survived & Death POD 71 \\
\hline
\end{tabular}


course, possibly due to the concomitant use of immunomodulatory drugs. ${ }^{18}$ This finding further enhances our confidence in excluding possible subclinical cases of COVID-19 when interpreting lymphopenia due to the effects of immunosuppressant therapy. During the routine follow-up visits of LTx recipients at the Wuxi Center, no cases of COVID-19 were reported to the center or during telemedicine-based consultations. However, the dose of immunosuppressant for post-COVID-19 LTx recipients should be modified on a case-by-case basis because of severe lymphopenia before transplantation. ${ }^{19}$ Critical patients with COVID-19 presented with cytokine release syndrome as a signature of immune function impairment. ${ }^{20}$ Although intensive life-support facilities were available for patients with negative NAT and positive serum SARS-CoV-2 IgG results, death was unavoidable in some patients unless urgent LTx was performed. ${ }^{21}$ All of the patients post-COVID-19 in our study received convalescent serum before transplantation, but none showed a sensitized status before transplantation. Cyclosporine A inhibited diverse coronaviruses, and it was safely administered to other transplant recipients. ${ }^{22}$ Tacrolimus was also safely used in the other regimen adopted at the Hangzhou Center. Close monitoring of the plasma concentration and lymphocyte, $\mathrm{CD} 4^{+}$, and $\mathrm{CD} 8^{+}$T-cell counts is particularly important.

There are more research results published on the fibrosispromoting environment observed in patients with severe COVID-19 from single-cell analysis ${ }^{23}$ and immune disturbance involving mechanisms, such as T-cell exhaustion during COVID-19 progression. ${ }^{24}$ Our data also verified that the death rate for critically ill patients with severe COVID-19 may be extremely high if they did not receive a transplant. Our transplant recipients post-COVID-19 exhibited a normalized level of interleukin- 6 and restored $\mathrm{CD}^{+} /$ $\mathrm{CD} 8^{+}$populations on immunosuppressants. The patient who died post-LTx at postoperative day 71 suggested that precise monitoring of immune status and drug modification still require improvement. We need to gain more experience and knowledge from the long-term follow-up of the surviving patients.

\section{Study Limitations}

The limitations of this study should be considered when interpreting the data given the retrospective nature of the analysis. The baseline characteristics of the patients varied with respect to underlying comorbidities, especially in critical patients with COVID-19. Confounder effects should be considered when determining the survival outcomes of LTx recipients between cohorts, which may require further investigation. We compared data from only 2 years because a renewed lung donation, transportation, and transplantation collaboration system has been established since September
2018 in China. We still need more data to demonstrate whether this system can operate during health crisis events, such as COVID-19, which may have an enormous impact on health systems in the entire nation. The uniqueness of the lung donation and allocation system in China and the Green Channel for lung transportation may differ from the systems in other countries. However, even if a globally decreasing trend of the COVID-19 pandemic is achieved and people face the "new normal" post-COVID-19 pandemic era, a new paradigm for lung donation and transportation should be considered to account for future uncertainty.

\section{CONCLUSIONS}

Our preliminary data described the feasibility and safety of lung donation and transplantation during the COVID-19 pandemic. Our initial efforts serve as a basis for management practices among transplant teams, thus safeguarding vulnerable donors, recipients, and related medical staff. In the context of the COVID-19 outbreak, the global community should work together to save lives and benefit patients.

\section{Conflict of Interest Statement}

The authors reported no conflicts of interest.

The Journal policy requires editors and reviewers to disclose conflicts of interest and to decline handling or reviewing manuscripts for which they may have a conflict of interest. The editors and reviewers of this article have no conflicts of interest.

China Lung Transplantation Alliance and National Lung Transplantation Expert Group for COVID-19: Bo Wu, MD (Wuxi Lung Transplant Center, Wuxi People's Hospital affiliated to Nanjing Medical University, Wuxi, China); Man Huang, MD (General ICU, Second Affiliated Hospital, Zhejiang University School of Medicine, Hangzhou, China); Guohui Jiao, MD, Chunxiao Hu, MD, and Xiaoshan Li, MD (Wuxi Lung Transplant Center, Wuxi People's Hospital affiliated to Nanjing Medical University, Wuxi, China); Gaofeng Zhao, MD (Department of Thoracic Surgery, the First Affiliated Hospital of Zhengzhou University, Zhengzhou, China); Weili Han, MD (Department of Lung Transplantation, the First Affiliated Hospital, Zhejiang University School of Medicine, Hangzhou, China); Jianxing He, MD (Department of Thoracic Surgery, The First Affiliated Hospital of Guangzhou Medical University, Guangzhou, China); Lu Guo, MD (Department of Respiratory Medicine, Sichuan People's Hospital, Chengdu, China); Wenhui Chen, MD (Center for Lung Transplantation, China-Japan Friendship Hospital, Beijing, China); Gening Jiang, MD (Department of Thoracic Surgery, Shanghai Pulmonary Hospital, Tongji University School of Medicine, Shanghai, China); Yi Yang, MD (Department of Critical Care Medicine, Zhongda Hospital, School of Medicine, Southeast University, Nanjing, China); and Jingyu Chen, MD (Wuxi Lung Transplant Center, Wuxi People's Hospital affiliated to Nanjing Medical University, Wuxi, China). 


\section{References}

1. Coronavirus disease (COVID-19) Situation Report - 193. Available at: https:// www.who.int/docs/default-source/coronaviruse/situation-reports/20200731-cov id-19-sitrep-193.pdf?sfvrsn=42a0221d_4. Accessed July 31, 2020.

2. Zhang BH, Yan LN, Yang JY. Organ transplantation management in the midst of the COVID-19 outbreak: a synopsis. Hepatobiliary Surg Nutr. 2020;9: 250-2.

3. Guidance from the International Society of Heart and Lung Transplantation regarding the SARS CoV-2 pandemic. Available at: https://ishlt.org/ishlt/ media/documents/SARS-CoV-2_-Guidance-for-Cardiothoracic-Transplant-andVAD-centers.pdf. Accessed July 31, 2020.

4. Guidance on Coronavirus Disease 2019 (COVID-19) for Transplant Clinicians; 2020. Available at: https://tts.org/tid-about/tid-presidents-message/23-tid/tidnews/657-tid-update-and-guidance-on- 2019-novel-coronavirus-2019-ncov-fortransplant-id-clinicians. Accessed July 31, 2020.

5. Wu B, Hu C, Chen W, He J, Jiang G, Zhang J, et al. China lung transplantation developing: past, present and future. Ann Transl Med. 2020;8:41.

6. Hu CX, Chen WH, He JX, Jiang GN, Li XS, Wei D, et al. Lung transplantation in China between 2015 and 2018. Chin Med J (Engl). 2019;132:2783-9.

7. Han W, Zhu M, Chen J, Zhang J, Zhu S, Li T, et al. Lung transplantation for elderly patients with end-stage COVID-19 pneumonia. Ann Surg. 2020;272: e33-4.

8. Kumar D, Manuel O, Natori Y, Egawa H, Grossi P, Han SH, et al. COVID-19: a global transplant perspective on successfully navigating a pandemic. Am J Transplant. 2020;20:1773-9.

9. Ianiro G, Mullish BH, Kelly CR, Sokol H, Kassam Z, Ng SC, et al. Screening of faecal microbiota transplant donors during the COVID-19 outbreak: suggestions for urgent updates from an international expert panel. Lancet Gastroenterol Hepatol. 2020;5:430-2.

10. European Society for Blood and Marrow Transplantation. Coronavirus disease COVID-19: updated EBMT recommendations; 2020. Available at: https:// www.ebmt.org/ebmt/news/ebmt- recommendation-corona virusdisease-covid19. Accessed March 6, 2020.

11. Maggi U, De Carlis L, Yiu D, Colledan M, Regalia E, Rossi G, et al. The impact of the COVID-19 outbreak on liver transplantation programs in Northern Italy. Am J Transplant. 2020;20:1840-8.

12. National Health Commission \& National Administration of Traditional Chinese Medicine. Diagnosis and treatment protocol for novel coronavirus pneumonia (Trial Version 7). Chin Med J. 2020;133:1087-95.
13. Bartlett RH, Ogino MT, Brodie D, McMullan DM, Lorusso R, MacLaren G, et al Initial ELSO guidance document: ECMO for COVID-19 patients with severe cardiopulmonary failure. ASAIO J. 2020;66:472-4.

14. Ostermann M, Connor M Jr, Kashani K. Continuous renal replacement therapy during extracorporeal membrane oxygenation: why, when and how? Curr Opin Crit Care. 2018;24:493-503.

15. Li SS, Miller R, Tumin D, Stewart WCL, Tobias JD, Hayes D Jr. Lung allocation score thresholds prioritize survival after lung transplantation. Chest. 2019;156: 64-70.

16. Tang A, Thuita L, Siddiqui HU, Rappaport J, Blackstone EH, McCurry KR et al. Urgently listed lung transplant patients have outcomes similar to those of electively listed patients. J Thorac Cardiovasc Surg. 2020 [Epub ahead of print].

17. Karakike E, Kyriazopoulou E, Tsangaris I, Routsi C, Vincent JL, GiamarellosBourboulis EJ. The early change of SOFA score as a prognostic marker of 28 day sepsis mortality: analysis through a derivation and a validation cohort. Crit Care. 2019;23:387.

18. Ren ZL, Hu R, Wang ZW, Zhang M, Ruan YL, Wu ZY, et al. Epidemiological and clinical characteristics of heart transplant recipients during the 2019 coronavirus outbreak in Wuhan, China: a descriptive survey report. J Heart Lung Transplant. 2020;39:412-7.

19. D'Antiga L. Coronaviruses and immunosuppressed patients. The facts during the third epidemic. Liver Transpl. 2020;26:832-4.

20. Moore JB, June CH. Cytokine release syndrome in severe COVID-19. Science. 2020;368:473-4.

21. Chen JY, Qiao K, Liu F, Wu B, Xu X, Jiao GQ, et al. Lung transplantation as therapeutic option in acute respiratory distress syndrome for COVID-19-related pulmonary fibrosis. Chin Med J (Engl). 2020;133:1390-6.

22. de Wilde AH, Zevenhoven-Dobbe JC, van der Meer Y, Thiel V, Narayanan K, Makino S, et al. Cyclosporin A inhibits the replication of diverse coronaviruses. J Gen Virol. 2011;92(Pt 11):2542-8.

23. Liao M, Liu Y, Yuan J, Wen Y, Xu G, Zhao J, et al. Single-cell landscape of bronchoalveolar immune cells in patients with COVID-19. Nat Med. 2020;26:842-4.

24. Ong EZ, Chan YFZ, Leong WY, Lee NMY, Kalimuddin S, Haja Mohideen SM, et al. A dynamic immune response shapes COVID-19 progression. Cell Host Microbe. 2020;27:879-82.e2.

Key Words: China, COVID-19, ECMO, lung transplantation, outcome 


\section{APPENDIX E1. INTRODUCTION OF CHINA LUNG TRANSPLANTATION ALLIANCE-COORDINATED LUNG DONATION AND TRANSPLANTATION WORKFLOW}

The following CLTA-coordinated workflow is established: When a donated lung is registered in the national allocation system, a listed candidate is matched to the donated lung. After the lung is procured, staff from the transplantation team of receiving centers or the LTx team from other centers nearby (also a member of CLTA) help transport the lungs to the receiving centers via the Green Channel of Human Organ Transportation within the shortest cold ischemic time. All of the LTx case data are submitted to the China Lung Transplantation Registry, which includes all the LTx institutions.

CLTA has been established since September 2018. The working model for lung donation and transportation has been changed. Under the supervision of the national allocation regulation agencies, LTx centers collaborate to make the maximum use of donations. Long-distance $(>300 \mathrm{~km})$ transported donations are increasing. Before September 2018, 2 days were needed to prepare the recovery staff, confirm the routes, and bring the organs to the LTx centers where recipients were located. However, under the CLTA framework, all the teams use the uniform protocol of lung recovery. When there is a donor, the recovery team in the nearest center will respond and take the shortest route to the donor location. When there was no COVID-19 in 2019 , the recovery team sent the organ directly to the receiving hospital and staffs met in the operation room. During the COVID-19 outbreak in 2020, the recovery team met the receiving staffs at the airport of the city where donors were located and handed over the donated lungs. There was no need for both teams to enter the city, avoiding the quarantine of the staff. The transportation time of the organ was not prolonged during the COVID-19 pandemic.

The Green Channel of Human Organ Transportation in China not only provides a fast track for security check of organs and staff but also works as a seamless connection of high-speed trains, commercial flights, and highways. Different combinations of transportation routes are chosen on the basis of the principle of shortest ischemic time of the organ. In the COVID-19 outbreak, there were multiple health checks at the entrance and exit of the cities; staff with donated organs had priority for boarding with guaranteed flight times with the approval in advance and filing from Green Channel of Human Organ Transportation. The transporting staff directly returned to their resident city on the next outbound flight; the process was coordinated by the Green Channel and airports/high-speed train stations. 


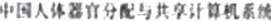

(4)

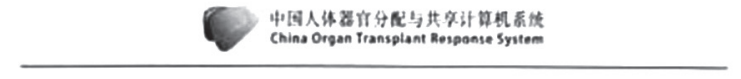

移植中心器官接收确认书

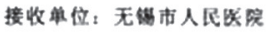

联系电话, 13812291811

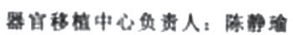

联系电话: 13358119213

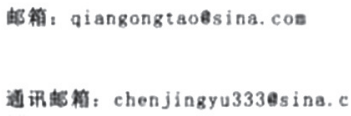

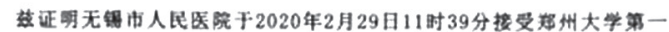

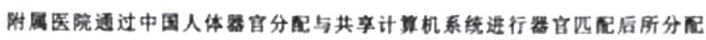

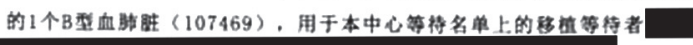
并要明

保证以下:

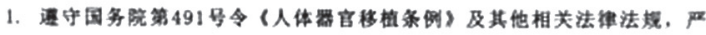

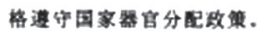

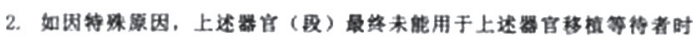

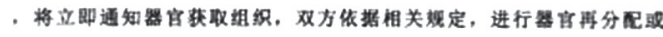
作合适处理。

3. 移析术后 72 小时内将接受者移酹等待名单. 并在双方协定的时间内向

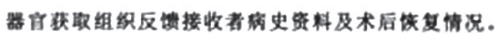

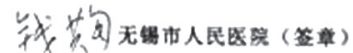

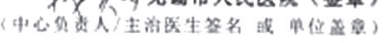

\section{椠州大学第一湖属医祭}

联系人: 韦费文

系电话: 13903835719

通讯码箱: fengguivenehotmail.
Translational version

China Organ Transplant Response System

Confirm of Receiving Donated Organs

Receiving transplant center:

Contact Tel:

Official email:

Person in charge of the transplant cente

Contact Tel:

Email:

This is to certify that (Receiving center name) has received a donated lung from (Donated center name) on ___ (Date and time). This organ has been matched and allocated through China Organ Transplant Response System. Blood type ___ (Allocation number). This organ has been allocated to (Recipient's name) on the waiting list, and will obey the following rules:

1. Fully conduct the Regulations on Human Organ Transplantation (Decree of No. 491 of the State Council) and related regulations and files, as well as the allocation policy;

2. If under any circumstance, such that the organ will be not transplanted to the nominated recipient on the waiting list, a notification should be sent to the organ procurement organization and reallocation procedure will be initiated;

3. The recipient's information will be removed from waiting list within $72 \mathrm{~h}$ post-transplantation. Required information from medical record and post-transplantation course will be submitted to organ procurement organization within commitment time.

Receiving transplant center (Signature)

Donation center:

(Barcode for identification)

Contact:

Tel:

Email:

FIGURE E1. Each transplant surgery was consented by qualified LTx centers. The listed patient's information was included in the Chinese Lung Transplant Registry system (http://www.cotr.cn/jsp/login/uLogin.jsp) and received final approval by the National Transplant Medical Review Board (Chinese Lung Transplantation Society and Transplantation Data Management \& Quality Control Center).

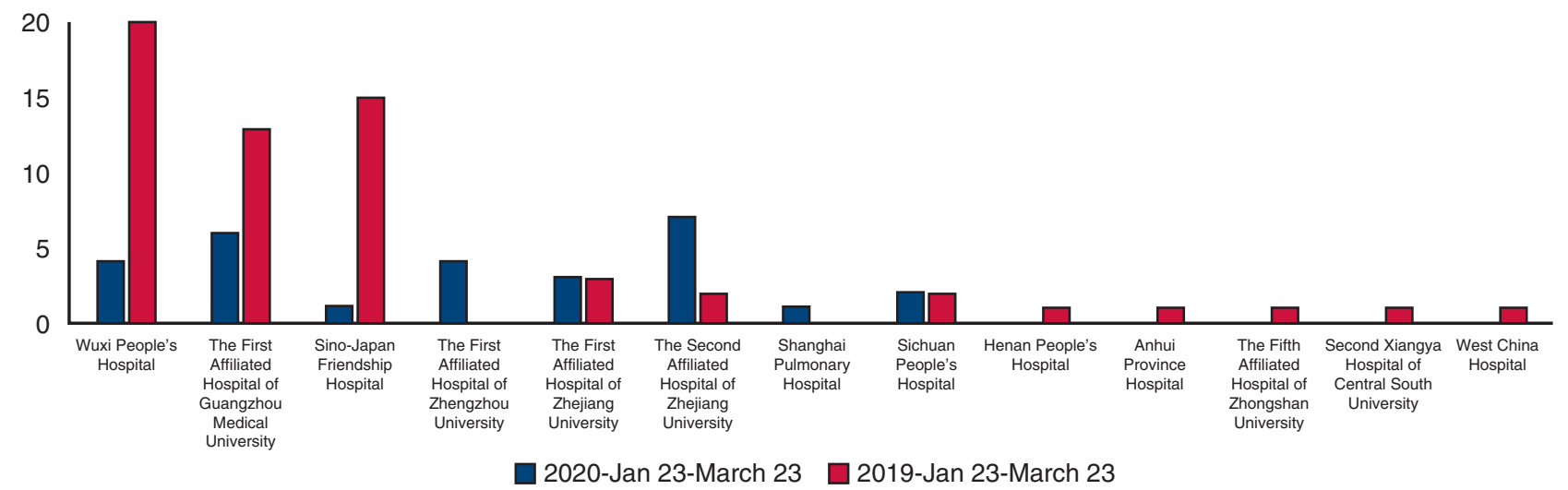

FIGURE E2. Comparison of LTx case volume within the same period of 2019 and 2020. 


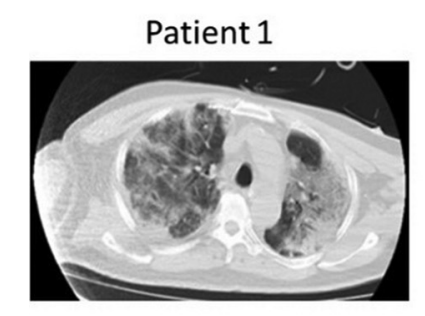

Patient 3

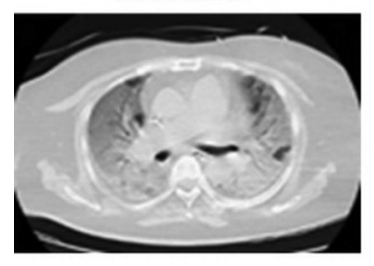

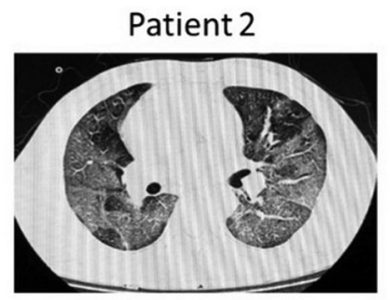

Patient 4

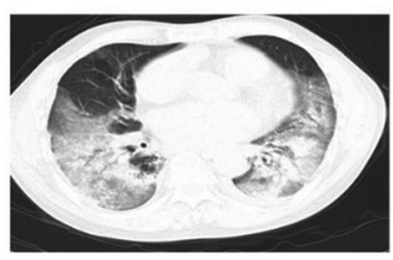

Patient 6

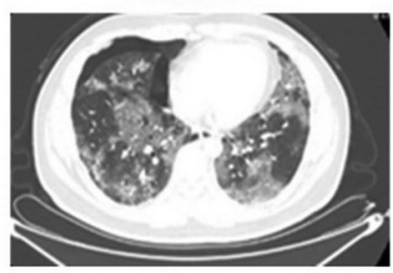

Patient 8

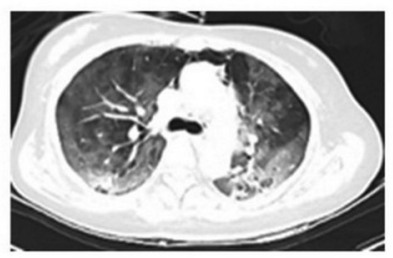

Patient 10

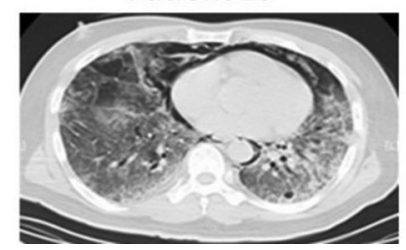

Patient 7

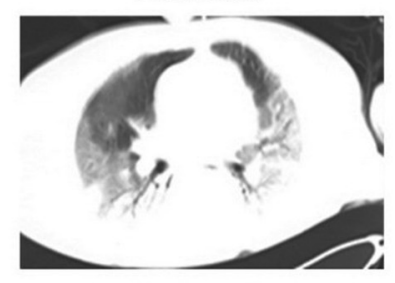

Patient 9

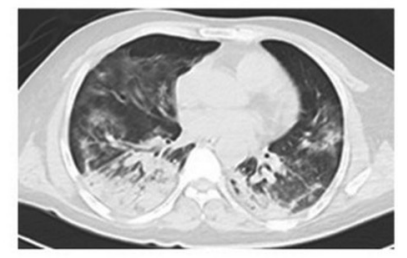

Patient 11

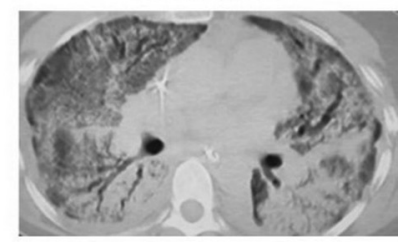

FIGURE E3. Patients post-COVID-19 who were referred for LTx assessment with computed tomography when available. Patients 1 to 4 were 4 of 5 transplant recipients who had computed tomography preoperatively. Patients 6 to 11 were 6 of 9 referred patients but did not receive transplant with available computed tomography images.

TABLE E1. Center distribution of lung transplant recipients from January 23 to March 23, 2020

\begin{tabular}{|c|c|c|c|c|}
\hline & $\begin{array}{c}\text { Transplant } \\
\text { volume }\end{array}$ & City/province & $\begin{array}{l}\text { If center is designated } \\
\text { for COVID-19 }\end{array}$ & $\begin{array}{c}\text { Risk } \\
\text { stratification* }\end{array}$ \\
\hline Wuxi People's Hospital/Wuxi communicable diseases hospital & 4 & Wuxi, Jiangsu & Yes & Medium \\
\hline The First Affiliated Hospital of Guangzhou Medical University & 6 & Guangzhou, Guangdong & Yes & Medium \\
\hline Sino-Japan Friendship Hospital & 1 & Beijing & No & Low \\
\hline The First Affiliated Hospital of Zhengzhou University & 4 & Zhengzhou, Henan & Yes & Medium \\
\hline The First Affiliated Hospital of Zhejiang University & 3 & Hangzhou, Zhejiang & Yes & Medium \\
\hline The Second Affiliated Hospital of Zhejiang University & 7 & Hangzhou, Zhejiang & No & Low \\
\hline Shanghai Pulmonary Hospital & 1 & Shanghai & No & Low \\
\hline Sichuan People's Hospital & 2 & Chengdu, Sichuan & Yes & Medium \\
\hline
\end{tabular}

Low risk: reported COVID-19 cases in local area, no direct contact with the hospital staffs and patients. Medium risk: COVID-19 cases admitted within 14 days, direct contact with the hospital staffs and patients. High risk: Hospital staff or patients admitted were infected by COVID-19 contact. COVID-19, Coronavirus Disease 2019. *Risk stratification and the center were evaluated upon transplantation performed. 
TABLE E2. Characteristics of patients post-Coronavirus Disease 2019 referred for lung transplantation who received and did not receive lung transplantation

\begin{tabular}{|c|c|c|c|}
\hline Characteristics & Nontransplant candidates $(\mathrm{N}=9)$ & LTx recipients $(N=5)$ & $P$ value \\
\hline \multicolumn{4}{|l|}{ Residency } \\
\hline Hubei Province* $(\%)$ & $3(33.3)$ & 0 & .26 \\
\hline Outside Hubei Province (\%) & $6(66.7)$ & $5(100)$ & \\
\hline Male $(\%)$ & $7(77.8)$ & $4(80)$ & 1.00 \\
\hline Age (y, Median [IQR]) & $53.7 \pm 13.6$ & $66.6 \pm 5.6$ & .07 \\
\hline BMI $\left(\mathrm{kg} / \mathrm{m}^{2}\right.$, Mean $\left.\pm \mathrm{SD}\right)$ & $26.8 \pm 2.4$ & $25.5 \pm 3.7$ & .59 \\
\hline \multicolumn{4}{|l|}{ Have underlying diseases } \\
\hline Hypertension & 2 & 2 & \\
\hline Hyperthyroidism & 1 & 0 & \\
\hline Diabetes mellitus & 0 & 2 & \\
\hline Chronic liver diseases & 0 & 1 & \\
\hline Psoriasis & 0 & 1 & \\
\hline MV (\%) & $8(88.9)$ & $5(100)$ & 1.00 \\
\hline Initial ECMO support (\%) & $9(100)$ & $5(100)$ & 1.00 \\
\hline Veno-venous $(\%)$ & $7(77.8)$ & $4(80)$ & \\
\hline Veno-arteriovenous $(\%)$ & $1(11.1)$ & $1(20)$ & \\
\hline Veno-arterial (\%) & $1(11.1)$ & & \\
\hline Continuous renal replacement therapy ( $\%)$ & $5(55.6)$ & $5(100)$ & .22 \\
\hline Tracheotomy $(\%)$ & $4(44.5)$ & $4(80)$ & .30 \\
\hline Convalescent plasma infusion ( $\%)$ & $2(22.2)$ & $3(60)$ & .27 \\
\hline Symptom onset to admission (median [IQR], d) & $4[2-10]$ & 7 [4-7] & 69 \\
\hline Admission to MV (Median [IQR], d) & $6.5[4-10.5]$ & 8 [2.75-9.5] & .93 \\
\hline MV to ECMO support (Median [IQR], d) & $2[1.5-5]$ & 13 [13-15] & .07 \\
\hline ECMO to LTx assessment (Median [IQR], d) & $57.5[46-62.25]$ & $10[8-10]$ & .00 \\
\hline Admission to virus clear (Median [IQR], d) & $22[20.5-46.5]$ & $21[21-23]$ & .26 \\
\hline Admission to LTx assessment (Median [IQR], d) & $65[58-71]$ & $31[31-32]$ & .00 \\
\hline $\mathrm{PaCO}_{2}$ before $\mathrm{ECMO}(\mathrm{mm} \mathrm{Hg})$ & $46.7 \pm 11.7$ & $53.6 \pm 9.6$ & .41 \\
\hline $\mathrm{EF}(\%$, Mean $\pm \mathrm{SD})$ & $54.4 \pm 4.5$ & $52 \pm 14.3$ & .76 \\
\hline Mean PAP $(\mathrm{mm} \mathrm{Hg}$, Mean \pm SD $)$ & $36.3 \pm 2.6$ & $46.7 \pm 4.9$ & .06 \\
\hline Lymphocytes $\left(* 10^{9} / \mathrm{L}\right.$, Mean $\left.\pm \mathrm{SD}\right)$ & $1.11 \pm 0.6$ & $0.57 \pm 0.1$ & .16 \\
\hline Hemoglobin $(\mathrm{g} / \mathrm{L}$, Mean $\pm \mathrm{SD})$ & $94 \pm 14.1$ & $90.3 \pm 2.2$ & .65 \\
\hline Platelets $\left(* 10^{9} / \mathrm{L}\right.$, Mean $\left.\pm \mathrm{SD}\right)$ & $112.8 \pm 70.5$ & $118.3 \pm 77.7$ & .93 \\
\hline D-Dimer $(m g / L$, Mean \pm SD) & $7.4 \pm 6.3$ & $15.4 \pm 3.4$ & .09 \\
\hline APTT $(s$, Mean \pm SD) & $42.5 \pm 14.1$ & $37.1 \pm 3.4$ & .59 \\
\hline Creatinine $(\mu \mathrm{moI} / \mathrm{L}$, Mean $\pm \mathrm{SD})$ & $58.7 \pm 20.7$ & $83.2 \pm 35.3$ & .29 \\
\hline $\mathrm{CRP}(\mathrm{mg} / \mathrm{L}$, Mean $\pm \mathrm{SD})$ & $149.9 \pm 66.3$ & $114.8 \pm 57.4$ & .49 \\
\hline Procalcitonin $(\mathrm{ng} / \mathrm{mL}$, Mean $\pm \mathrm{SD})$ & $0.75 \pm 0.6$ & $1.1 \pm 0.6$ & .50 \\
\hline LAS score & $82.7[63.3-84.2]$ & $80.9[64.2-82.3]$ & .65 \\
\hline SOFA score & $13[12-13]$ & $15.5[14.75-16.5]$ & .00 \\
\hline SOFA score post-LTx $7 \mathrm{~d}$ & & $4[3.5-4.5]$ & \\
\hline Survival without LTx (\%) & $3(33.3)$ & & \\
\hline Post-LTx $30 \mathrm{~d}$ survival (\%) & & $4(80)$ & \\
\hline
\end{tabular}

Bold indicates statistical significance $(P<.05)$. $L T x$, Lung transplantation; $I Q R$, interquartile range; $B M I$, body mass index; $S D$, standard deviation; $M V$, mechanical ventilation; $E C M O$, extracorporeal membrane oxygenation; $E F$, ejection fraction; $P A P$, pulmonary artery pressure; $A P T T$, activated partial thromboplastin time; $C R P, \mathrm{C}$-reactive protein; $L A S$, Lung Allocation Score; SOFA, Sequential Organ Failure Assessment. *Wuhan is in Hubei Province, where a large number of COVID-19 cases were located, and lockdown measures were adopted during the COVID-19 pandemic. 
TABLE E3. Approaches for lung donation and transplantation during Coronavirus Disease 2019 pandemic

1. Potential donor in the donation center

1.1 Precondition for donation

$\square$ No confirmed case in the past $14 \mathrm{~d}$ if they are in high-risk regions

$\square$ Have collaboration with a regional center for contagious diseases with regard to laboratory tests and preventive measures

$\square$ Prepare an isolated single medical unit for organ donation, separated from families

1.2 Donor assessment

$\square$ Meet all the conventional requirements of organ donation

$\square$ Not exposed to a patient with confirmed or suspected COVID-19 within $14 \mathrm{~d}$

$\square$ No clinical manifestations of COVID-19

$\square$ Should have at least 2 negative results obtained from consecutive testing of nasopharyngeal swab specimens by NAT for SARS-CoV-2

$\square$ No signs of pneumonia on CT

1.3 Donor maintenance

$\square$ Remain in a single medical unit with no confirmed or suspected cases nearby

$\square$ Dedicated medical staff responsible for routine care

$\square$ Perform disinfection daily in the ward and after each case

1.4 Family members/close contacts

$\square$ No history of travel to affected regions/contact with affected individuals

$\square$ No clinical or chest imaging manifestations of COVID-19

$\square$ If suspected to be infected, a nasopharyngeal sample test for SARS-CoV-2 by NAT performed

$\square$ Wear masks, adhere to hand hygiene recommendations, and cooperate with dynamic surveillance for SARS-CoV-2

1.5 Logistic management

$\square$ Establish a telemedicine-based consultation platform for donation logistics coordination

$\square$ Local recovery and procure team for seamless transportation to the recipient's hospital

2. Recipients on the waiting list

2.1 Precondition for transplantation

$\square$ Not exposed to a patient with confirmed or suspected COVID-19 within $14 \mathrm{~d}$

$\square$ No clinical manifestations of COVID-19

$\square$ Should have at least 2 negative results obtained from consecutive testing of nasopharyngeal swab specimens by NAT for SARS-CoV-2

$\square$ No signs of pneumonia on CT

$\square$ If necessary, transferred via private transportation to the nearest center of excellence

2.2 Admitted for transplantation surgery

2.2.1 Physical preparedness

$\square$ Admitted in a single medical unit with no confirmed or suspected cases nearby

$\square$ Admitted in rooms with adequate disinfection and air circulation

$\square$ Dedicated medical staff responsible for routine care

$\square$ Confirm low levels of inflammatory markers and no signs of rapid progression on CT related to COVID-19 infection

$\square$ Determine if the estimated transfusion volume exceeds the amount available in the blood bank

$\square$ Be educated regarding prevention measures, in cooperation with their families

$\square$ Adhere to hand hygiene standards, and cooperate with dynamic surveillance for SARS-CoV-2

$\square$ Receive adequate nutritional support and pulmonary rehabilitation

2.2.2 Psychological preparedness

$\square$ Fully consent to transplantation after being informed about the risk of SAR-CoV-2 infection in the perioperative period

$\square$ Undergo psychological counseling to reduce stress and anxiety

2.3 Family members/close contacts

$\square$ No history of travel to affected regions/contact with affected individuals

$\square$ No clinical or chest imaging manifestations of COVID-19

$\square$ If suspected to be infected, a nasopharyngeal sample test for SARS-CoV-2 by NAT performed

$\square$ Wear masks, adhere to hand hygiene recommendations, and cooperate with dynamic surveillance for SARS-CoV-2

$\square$ Be informed of their legal responsibility if they deliberately falsely deny any contact history and should sign the appropriate forms

3. Lung donation commissioning

3.1 Procurement team preparedness

$\square$ Not exposed to a patient with confirmed or suspected COVID-19 within $14 \mathrm{~d}$

$\square$ Trained in self-protective measures against COVID-19

$\square$ Updated personal health status and perform contact tracing, with the results reported to the department of hospital infection control

3.2 Lung procurement

$\square$ Take proper protective measures according to the protection level of the donation center 
TABLE E3. Continued

$\square$ Avoid entering emergency department, ICU, and COVID-19 isolation and observation ward

$\square$ Wear surgical masks and adhere to appropriate hand hygiene standards when communicating with the family members of decedents

$\square$ Sterilize the medical facilities after the procedure, packaging all disposables as biohazards

3.3 Keep receiving center updated

$\square$ Contact medical staff through voice and video communication instead of field inspection

3.4 On-route transportation

$\square$ Go through the "green channel" procedure with barcoded allocation identification

$\square$ Escort the donated organ in an adequately disinfected hospital ambulance

$\square$ Obtain approval for transportation in advance from security in airports

$\square$ If escorted by receiving center's staff, the staff should not attend surgery avoiding unnecessary contact

4 Lung transplantation surgery

$\square$ Staff undergo training with regard to updated prevention strategies for COVID-19

$\square$ Staff update the department of hospital infection control daily with regard to their personal health condition

$\square$ Staff wear personal protective equipment according to the stratification of infection risk

$\square$ Staff use disposable medical resources to avoid cross-infection and disinfect nondisposable resources after each patient

5 Post-transplant care

5.1 Physical support

$\square$ Use respirators with filters and disposable valves

$\square$ No frequent ventilator tube changes to avoid aerosols

$\square$ Bronchoscopy with single-use materials to avoid cross-infection

$\square$ Receive appropriate sedatives when undergoing invasive ventilation

$\square$ Early mobilization and rehabilitation

$\square$ If manifesting a fever of unknown origin, tested for SARS-CoV-2 by NAT and IgM/IgG

$\square$ After discharge, undergo routine follow-up through telemedicine-based clinics

5.2 Psychological support

$\square$ Reduced access to information from mass media and participate in video communication with family

$\square$ Psychological counseling along with their family to reduce stress and anxiety

COVID-19, Coronavirus Disease 2019; $N A T$, nucleic acid test; $S A R S-C o V-2$, severe acute respiratory syndrome coronavirus 2; $C T$, computed tomography; ICU, intensive care unit; $I g$, immunoglobulin. 